\title{
Plateau Tibial Fractures are Associated with High Rates of Major Ligaments Ruptures
}

\section{Manuel Mosquera ${ }^{1 *}$, Juan Ricardo Gil' ${ }^{2}$, Juan Manuel Mosquera ${ }^{3}$, David Portilla $^{3}$, Andrés Felipe Vence ${ }^{3}$ and Yessica Paola González $\mathrm{F}^{4}$}

${ }^{1}$ Orthopedist, Clínica Erasmo, Valledupar, Clínica La Carolina, Bogota, Colombia

${ }^{2}$ Orthopedist, Clínica Erasmo, Valledupar, Colombia

${ }^{3}$ General Practitioner, Clínica Erasmo, Valledupar, Colombia

${ }^{4}$ Physiotherapist, Research Coordinator, Clínica Erasmo, Valledupar, Colombia

*Corresponding Author: Manuel Mosquera, Orthopedist, Clínica Erasmo,

Valledupar, Clínica La Carolina, Bogota, Colombia.
Received: April 22, 2021

Published: May 17, 2021

(C) All rights are reserved by Manuel

Mosquera., et al.

\section{Abstract}

Summary: Tibial Plateau fractures are injuries that usually result from high energy trauma, especially those involving motorcycle accidents. The association of meniscal and ligament injuries in this type of fracture is described in the literature, especially grade IV, $\mathrm{V}$ and VI, according to the Schatzker classification.

Purpose: To know the frequency of injuries of the major ligaments in patients with tibial plateau fracture according to the Schatzker classification and to present a sub-group of patients intervened due to anterior and/or posterior instability, describing the type of lesion, its location, the treatment used and the short-term follow-up.

Materials and Methods: We reviewed the medical records of the patients who were diagnosed with tibial plateau fracture from January 2014 to January 2018, analyzing the type of fracture according to Schatzker and those who presented secondary ligament instability diagnosed after the consolidation of the fracture.

Results: A total of 302 patients with tibial plateau fractures were presented, of which 63 (20.8\%) had involvement of one or more of the major ligaments. The lesions occurred in all types of fracture primarily in type II, V and VI. The most frequent ligament torn was the Anterior Cruciate Ligament (ACL) in 52 patients (17.2\%), with the type II fracture causing the most injury. Of the 63 patients with instability, for administrative reasons only 13 patients (20\%) were operated, 11 of whom had ACL injury. 91\% of the ligament injuries found at the time of surgery preserved a large part of their remnant's fibers with elongation.

Conclusion: Tibial plateau fractures have a high association of lesions in the major ligaments, presenting in this study in one per five patients.

Keywords: Plateau Tibial Fractures

\section{Introduction}

Tibial plateau fractures are injuries that usually result from high-energy trauma, especially those involving motorcycle accidents, taking into account that the knee is exposed to direct blow.
These fractures have been classified by Schatzker and collaborators (colbs) [1] in degrees depending on the commitment of one or both plateaus and if there is also a connection with the tibial shaft. In recent years, the AO Classification has been used, which 
introduces other variants and more recently the Luo classification [2], taking into account the concept of the three columns as a principle in the diagnosis and treatment strategy. It is described in the literature the association of meniscal and ligamentous lesions in this type of fractures, especially grade IV, V and VI [3-6]. However, in many trauma centers the initial diagnosis of these injuries is not made either because they do not take magnetic resonance studies (MRI) or because most of the approaches in this type of fractures do not include arthroscopy as a tool in their diagnosis and treatment [7]. By having intra-articular compromise they always injure the cartilage with the consequence of generating degenerative disease in the medium and long term, however some patients consult early in the follow-up for symptoms of instability or pain due to ligament and/or meniscal lesions that are usually not diagnoses from the beginning [8].

\section{Purpose of the Study}

To know the frequency of mayor knee ligament lesions in patients with tibial plateau fracture in the Erasmo clinic over a period of 4 years according to the Schatzker classification and to present a subgroup of patients operated for anterior and/or posterior instability, for lesions of the ACL and PCL, describing the type of injury, its location, the treatment used and its short-term clinical outcome.

\section{Materials and Methods}

A descriptive retrospective study was carried out. The medical records of all patients who in the emergency department were diagnosed with a tibial plateau fracture (S821) from January 2014 to January 2018 were reviewed. The analysis included the type of fracture according to the Schatzker classification and the clinical and MRI evaluation after consolidation and removal of osteosynthesis material, determining the presence of instability, the direction of instability and injured ligament (s). In a subgroup of operated patients, the location of the rupture, pattern of the rupture was described if it was a partial or complete lesion, if there was elongation, or avulsion. Complications and short-term clinical outcome were analyzed.

Inclusion criteria: Young patients between the ages of 18 and 60, with a history of fracture of the tibial plateau (s) with a diagnosis of knee instability due to ligament injury. For the subgroup of patients undergoing surgery, a minimum of 12 months of clinical follow-up.
Exclusion criteria: Avulsions of the anterior tibial spine, joint instability due to bone defect, previous osteoarthritis and patients over 60 years.

\section{Statistical analysis}

For the statistical analysis, the SPSS version 15.0 program for Windows was used. The normality assumption was evaluated with the parametric test of Shapiro Wilk showing normality. Descriptive analysis was performed with $\mathrm{T}$ tests for independent samples such as: gender, age, laterality, procedure and classification of fractures; $\mathrm{T}$ tests were applied for related samples of the specific tests of anterior and posterior drawer, lateral and medial test, Lachman, pivot and dial test. Eleven patients were evaluated using the IKDC scale before and after surgery.

\section{Results}

302 patients were operated for tibial plateau fracture from January 2014 to January 2018, distributed according to the Schatzker classification as shown on table 1 . The study population was characterized with demographic data showing that the male gender was the most affected with $75.5 \%$. The age range was 24 to 60 years with an average of 39 years; and the most affected member was the left with $87.5 \%$. The most frequent type of tibial plateau fracture was Schatzker II with 101 patients corresponding to $37.5 \%$ and the most affected column according to the Luo classification was the posterior column in 151 patients corresponding to $50 \%$ of all cases.

\begin{tabular}{|l|c|}
\hline \multicolumn{2}{|c|}{ Total relations } \\
\hline Fractures total patients knee & 302 \\
Instability patients operated & 63 \\
Patients & 13 \\
Follow up & 8 \\
\hline Schatzker classification according patient number \\
\hline Schatzker I & 29 \\
Schatzker II & 101 \\
Schatzker III & 7 \\
Schatzker IV & 29 \\
Schatzker V & 70 \\
Schatzker VI & 66 \\
\hline
\end{tabular}

Table 1: Total relations. 
Of the total, 63 patients (20.8\%) presented in the follow-up, ligament instability determined by the clinical evaluation after the fracture was consolidated. The distribution of the type of ligament (s) involved is shown in table 2. The anterior cruciate ligament injury in this study was presented in 52 patients corresponding to $17.2 \%$ and the posterior cruciate ligament in 6 patients corresponding to $1.99 \%$. Doing the analysis of ACL injuries by type of fracture according to the Schatzker classification we found 4 patients with type I (7.7\%), 21 patients with type II (40.3\%), 1 patient with type III (2\%), 4 patients with type IV (7.7\%), 13 patients with type V (25\%) and 9 patients with type VI (17.3\%). PCL injury occurred more frequently in type II and IV fractures.

\begin{tabular}{|l|c|c|}
\hline \multicolumn{1}{|c|}{ Instability } & Number & Schatzker \\
\hline ACL & 40 & I(4), II(15), IV(5),V(8), VI(8) \\
\hline PCL & 5 & II(1), III(1), IV(2), VI(1) \\
\hline MCL & 2 & V(1), VI(1) \\
\hline LCL & 1 & V(1) \\
\hline ACL+MCL & 7 & II(2), V(4), VI(1) \\
\hline ACL + LCL & 3 & II(2), III(1) \\
\hline ACL + PCL & 1 & II(1) \\
\hline PCL + MCL & 1 & II(1) \\
\hline PCL +LCL & 1 & VI(1) \\
\hline LCL + MCL & 1 & V(1) \\
\hline ACL + PCL +MCL & 1 & V(1) \\
\hline
\end{tabular}

Table 2: Distribution of instability type and relationship according to Schatzker.

Table 3 shows the percentage of instability taking into account the type of fracture, the type III being the highest with $28 \%$, followed by the type IV and V fracture.

Of the 63 patients with instability, only 13 patients were operated (20.6\%) and the others 50 patients were referrals to their insurance's companies. The procedures performed in table 4 are detailed in these 13 patients. The most frequent surgical procedure was the reconstruction of the ACL and/or PCL using the augmentation technique by $84.6 \%$, as shown in table 4 . Augmentation means to perform a selected bundle reconstruction in case of partial ruptures and preserve the remnant [9]. Within the intraoperative findings, we found that in 11 patients there was a good quality remnant that allowed us to preserve it. In 9 ACL cases we

\begin{tabular}{|l|c|c|c|}
\hline \multicolumn{2}{|c|}{ Schatzker classification according knee instability } \\
\hline $\begin{array}{c}\text { Shatzker } \\
\text { Classification }\end{array}$ & $\begin{array}{c}\text { Total } \\
\text { Amount }\end{array}$ & $\begin{array}{c}\text { Instability } \\
\text { Patient } \\
\text { Number }\end{array}$ & Percentage \\
\hline I & 29 & 4 & 13.8 \\
\hline II & 101 & 22 & 21.8 \\
\hline III & 7 & 2 & 28.6 \\
\hline IV & 29 & 7 & 24.1 \\
\hline V & 70 & 16 & 22.9 \\
\hline VI & 66 & 12 & 18.2 \\
\hline
\end{tabular}

Table 3: Schatzker classification according knee instability.

performed posterolateral bundle augmentation technique with AM preservation, and in 2 of these 11 patients in addition, we reinsert the remnant to restore it tension using high strength sutures fixed on the femur with knotless. For the PCL cases, augmentation of the posteromedial bundle were made in all cases. Just 2 patients of these 13 had a conventional ACL reconstruction.

\begin{tabular}{|l|c|c|}
\hline & Frequency & Percentage \\
\hline ACL augmentation & 6 & 46.2 \\
\hline $\begin{array}{l}\text { ACL augmentation } \\
\text { + reinsertion }\end{array}$ & 2 & 15.4 \\
\hline $\begin{array}{l}\text { What ACL+PCL } \\
\text { augmentation }\end{array}$ & 1 & 7.7 \\
\hline PCL augmentation & 2 & 15.4 \\
\hline ACL 50/50 & 2 & 15.4 \\
\hline Total & 13 & 100.0 \\
\hline
\end{tabular}

Table 4: Type of procedures.

What does ACL augmentation and reinsertion mean

Only 8 patients could be followed in the post-operative evaluation between 8 and 24 months with an average of 14 Is 8 patient i.e. about $45 \%$ enough numbers to do statics. To these patients the Tegner and Lysholm score scale was applied, showing that 87.5. $\%$ were rated as excellent and good and only one patient $(12.5 \%)$ was rated as regular for an arthrofibrosis who had undergone an ACL augmentation. At the end of the follow-up the knee was stable. Table 5 describes $\mathrm{T}$ tests for related samples evidencing statistical significance for the Lachman test and the IKDC (Table 5). Related 
samples test Related differences Sig. (Bilateral) Average standard deviation.

\begin{tabular}{|l|c|c|c|c|}
\hline \multicolumn{2}{|c|}{ Media } & \multicolumn{2}{c|}{ Related differences } & \multirow{2}{*}{$\begin{array}{c}\text { Sig. } \\
\text { (bilateral) }\end{array}$} \\
\cline { 3 - 4 } & $\begin{array}{c}\text { Deviation } \\
\text { STD }\end{array}$ & & 0.064 \\
\hline Par 1 & $\begin{array}{c}\text { Drawer Test Pre } \\
\text { Drawer Test Post }\end{array}$ & 0.87500 & 1.12599 & 0.170 \\
\hline Par 2 & $\begin{array}{c}\text { Drawer Post Pre } \\
\text { Drawer Test Post }\end{array}$ & 0.50000 & 0.92582 & $0.008 *$ \\
\hline Par 3 & $\begin{array}{c}\text { Lachman_Pre-Lach- } \\
\text { man_Post }\end{array}$ & 1.37500 & 1.06066 & 0.0 .351 \\
\hline Par 4 & $\begin{array}{c}\text { Open Lateral Pre } \\
\text { Open Lateral Post }\end{array}$ & 0.12500 & 0.35355 & 0.351 \\
\hline Par 5 & $\begin{array}{c}\text { Open Medial Pre } \\
\text { Open Medial Post }\end{array}$ & -0.12500 & 0.35355 & 0.351 \\
\hline Par 6 & Pivot_Pre - Pivot_Post & 0.12500 & 0.83452 & 0.685 \\
\hline Par 8 & IKDC_Pre- IKDC_Post & -40.78750 & 19.44233 & $0.001^{*}$ \\
\hline
\end{tabular}

Table 5: Related differences test.

\section{Discussion}

Fractures around the knee correspond to $6 \%$ of all injuries received in the emergency services [9]. Their initial management is aimed to resolving joint and metaphyseal congruence, however not only this define the final outcome of the patients, taking in account that these fractures especially plateau fractures are very often associated with soft tissue injuries that include the 4 major ligaments of the knee, menisci and articular cartilage [10]. Despite the above, in the emergency services, magnetic resonance imaging is not a routine examination for this kind of trauma where conventional $\mathrm{x}$ ray and CT are still the gold standard tests for the proper diagnosis and classification of the fracture. In some centers they use MRI as a tool to diagnose soft tissue lesions in this type of fractures [11]. The use of arthroscopy has been recommended as a useful instrument to aid in the reduction of fragments even in complex fractures and also to diagnose and treat as much as possible the associated lesions, especially the tears of the anterior horn of the lateral meniscus [12]. However, open reduction remains the most used approach to treat these fractures and in many cases the diagnosis of associated lesions is not made it and are the patient who complain about instability symptoms in their clinical evolution after consolidation. There are a great variability in the frequency of major liga- ment injuries and especially with the cruciate ligaments reported in the literature. Shtazker reported 7\%, Delamarter., et al. reported 1 single ACL injury in 39 patients [13], Bennet found 10\% ACL [14] lesions, while Abdel Hamid., et al. found 25\% ACL injuries and 10\% PCL [15]. Colleti [16] identified a high percentage of ACL lesions in $41 \%$ and for PCL $28 \%$, as Gardner [17] who reported $47 \%$ of ACL lesions reported by resonance analysis. Our study found 52 lesions of the ACL and 6 lesions of the PCL in 302 patients, corresponding to a rate of $20.8 \%$ that is consistent with that reported in the literature. Our attention is draw with the high frequency of ACL and PCL lesions with Shatzker's type II fracture occurred in 22 patients out of 63 , corresponding to $35 \%$, exceeding the type IV, V, and VI fractures reported by the literature, however, cruciate ligament injuries were present in all types of fractures, with type V and VI fractures being the ones that reported more cruciate ligament injuries after those of type II. 14 patients (22\%) had collateral ligament injuries in all types of Shatzker except in type I. Of the 13 patients who underwent surgery, it is noticeable that the prevalent pattern of ligament injury of both cruciates is proximal avulsion and/or elongation, which allowed us to preserve the remnant in 11 patients and in two of these, it was also possible to reinsert correcting the laxity found it. The technique we used to reinsert the remnant is to pass two or three high strength sutures through the remnant as cinches and fixed it in the center of the bundle on the proximal femur $[18,19]$. Of the 8 patients who met the minimum follow-up, only 1 patient was rated with a regular result according to the Tegner and Lysholm scales and the other 7 with excellent and good results. As it is a small sample, we cannot give conclusions in this regard, however we must note that there is (just one) study published in the literature that reports the clinical result after ligament reconstruction in patients with a history of tibial plateau fracture [20].

\section{Conclusion}

There is a high frequency of associated injuries of the cruciate ligaments of the knee in fractures of the tibial plateau and in this study was $20.8 \%$, similar to some papers published in the literature. It should draw our attention when we treat this type of fractures to achieve a final good result of these patients.

Why was luo classification not used as it would make more sense to understand instability? (This article do not deal with the proper diagnosis, planning and treatment of this plateau fractures 
where the Luo or modified Schatzker classification are better to do it, so this paper only intent describe the association of these fractures and mayor knee ligaments disruption).

\section{Disclosure}

The authors declare that they have no conflict of interest in the presentation of this paper. All authors contributed to this investigation.

\section{Bibliography}

1. Schatzker J., et al. "The tibial plateau fracture: the Toronto experience: 1968-1975". Clinical Orthopaedics and Related Research 138 (1979): 94-104.

2. Luo CF., et al. "Three-column fixation for complex tibial plateau fractures". Journal of Orthopaedic Trauma 24 (2010): 683-692.

3. Tang HC., et al. "Correlation of parameters on preoperative CT images with intra-articular soft-tissue injuries in acute tibial plateau fractures: A review of 132 patients receiving ARIF". Injury 48.3 (2017): 745-750.

4. Porrino J., et al. "Association of Tibial Plateau Fracture Morphology With Ligament Disruption in the Context of Multiligament Knee Injury". Current Problems in Diagnostic Radiology 47.6 (2018): 410-416.

5. Spiro AS., et al. "The degree of articular depression as a predictor of soft-tissue injuries in tibial Plateau fracture". Knee Surgery, Sports Traumatology, Arthroscopy 21.3 (2013): 564-570.

6. Gardner MJ., et al. "The incidence of soft tissue injury in operative tibial plateau fractures: a magnetic resonance imaging analysis of 103 patients". Orthopaedic Trauma 19.2 (2005): 7984.

7. Abdel-Hamid MZ., et al. "Artroscópica evaluación of soft tissue injuries in tibial plateau fractures: retrospective analysis of 98 cases". Arthroscopy 22.6 (2006): 669-675.

8. Ebrahimzadeh MH., et al. "Clinical instability of the knee and functional differences following tibial plateau fractures versus distal femoral fractures". Trauma Monthly 20.1 (2015).

9. Ferran Abat., et al. "Promising short-term results following selective bundle reconstruction in partial anterior cruciate ligament tears 20.5 (2013): 332-338.

10. Adeeb M and Moran CG. "Fractures around the Knee". Surg 21.9 (2003): 228-230.

11. Delamarter RB., et al. "Ligament injuries associated with tibial plateau fractures". Clinical Orthopaedics and Related Research 250 (1990): 226-233.
12. Shepherd L., et al. "The prevalence of soft tissue injuries in nonoperative tibial plateau fractures as determined by magnetic resonance imaging". Journal of Orthopaedic Trauma 16.9 (2002): 628-631.

13. Abdel-Hamid MZ., et al. "Artroscópica evaluación of soft tissue injuries in tibial plateau fractures: retrospective analysis of 98 cases". Arthroscopy 6 (2006): 669-675.

14. Delamarter RBv. "Ligament injuries associated with tibial plateau fractures". Clinical Orthopaedics and Related Research 250 (1990): 226-233.

15. Bennett WF and Browner B. "Tibial plateau fractures: a study of associated soft tissue injuries". Journal of Orthopaedic Trauma 8.3 (1994): 183-188.

16. Abdel-Hamid MZ., et al. "Arthroscopic evaluation of soft tissue injuries in tibial plateau fractures: retrospective analysis of 98 cases". Arthroscopy 22.6 (2006): 669-675.

17. Colletti P., et al. "MR findings in patients with acute tibial plateau fractures". Computerized Medical Imaging and Graphics 20.5 (1966): 389-394.

18. Gardner MJ., et al. "The incidence of soft tissue injury in operative tibial plateau fractures: a magnetic resonance imaging analysis of 103 patients". Journal of Orthopaedic Trauma 19.2 (2005): 79-84.

19. Vanh Der List J., et al. "Arthroscopic primary repair of proximal anterior cruciate ligament tears seems safe but higher level of evidence is needed: a systematic review and meta-analysis of recent literature". Knee Surgery, Sports Traumatology, Arthroscopy 28.6 (2020): 1946-1957.

20. Jiang L., et al. "Two Cases of Contact Anterior Cruciate Ligament Rupture Combined with a Posterolateral Tibial Plateau Fracture". Case Reports in Orthopedics (2015): 250487.

\section{Volume 4 Issue 6 June 2021}

(C) All rights are reserved by Manuel Mosquera., et al. 